\title{
DERECHO Y POLÍTICAS AMBIENTALES EN LA COMUNIDAD DE MADRID
} (PRIMER SEMESTRE 2021)

\author{
DANIEL B. ENTRENA RUIZ \\ Profesor Contratado Doctor \\ Universidad Carlos III de Madrid ${ }^{1}$ \\ daniel.entrena@uc3m.es
}

\begin{abstract}
SUMARIO: 1.- Decreto 7/2021, de 27 de enero, del Consejo de Gobierno, por el que se aprueba el Reglamento de Vías Pecuarias de la Comunidad de Madrid. 2.- Resolución de 2 de febrero de 2021, de la Dirección General de Sostenibilidad y Cambio Climático, por la que se aprueba el Plan de Acción contra el Ruido de la Red de Carreteras de la Comunidad de Madrid 2018-2023. 3.Resolución de 16 de febrero de 2021, del Director General de Biodiversidad y Recursos Naturales, de la Consejería de Medio Ambiente, Ordenación del Territorio y Sostenibilidad, por la que se regula el tránsito por viales, el tránsito en las inmediaciones y pie de vía de sectores de escalada y la escalada en los sectores y vías regulados, en el paraje de La Pedriza del Parque Nacional de la Sierra de Guadarrama como medida de protección de especies rupícolas durante su época de cría y reproducción. 4.- Orden 608/2021, de 10 de marzo, de la Consejería de Medio Ambiente, Ordenación del Territorio y Sostenibilidad, sobre establecimiento de vedas y regulación especial de la actividad piscícola en los ríos, arroyos y embalses de la Comunidad de Madrid, para la temporada 2021
\end{abstract}

\section{1.- Decreto 7/2021, de 27 de enero, del Consejo de Gobierno, por el que se aprueba el Reglamento de Vías Pecuarias de la Comunidad de Madrid: legitimación de su uso para actividades sociales recreativas.}

La Ley 3/1995, de 23 de marzo, de Vías Pecuarias, el Estado estableció el régimen jurídico de estos bienes de dominio público, ejerciendo la competencia que le atribuye el artículo 149.1.23 de la Constitución para dictar la legislación básica sobre esta materia. Posteriormente, en la Comunidad de Madrid, aprobó la Ley 8/1998, de

\footnotetext{
${ }^{1}$ Open Researcher and Contributor ID (ORCID): 0000-0003-1393-0736
} 
15 de junio, de Vías Pecuarias, que prevé en su disposición final segunda su ulterior desarrollo reglamentario, que tenía que haberse producido en el plazo de un año.

Así, con casi 22 años de retraso se produce ahora el desarrollo reglamentario de la Ley madrileña, según indica la exposición de motivos del texto complementario, en torno a tres ejes fundamentales: i) la incorporación de los principios de buena regulación, contenidos en el artículo 129 de la Ley 39/2015, de 1 de octubre, del Procedimiento Administrativo Común de las Administraciones Públicas; ii) la adaptación de los procedimientos a los principios establecidos en la normativa patrimonial promulgada con posterioridad a la entrada en vigor de las leyes estatal y autonómica en materia de vías pecuarias, reforzando específicamente los de simplificación, agilidad y participación; iii) una mayor eficacia del derecho de los ciudadanos a disfrutar de un medio ambiente adecuado, así como, el deber de conservarlo (artículo $45 \mathrm{CE}$ ), en particular al incorporar un procedimiento de responsabilidad ambiental, que incluye la obligación de reparar, o en su caso, indemnizar los daños provocados en vías pecuarias.

Ante la imposibilidad de describir el conjunto del articulado, deseamos destacar un aspecto que ha sido polémico en la Comunidad de Madrid, y que es exponente de esos tres ejes: el régimen usos mediante instalaciones desmontables en vías pecuarias, en particular cuando se encuentran asociadas a actividades de servicios.

Conforme a la Ley $3 / 1995$, de 23 de marzo de Vías Pecuarias, puesto que éstas se encuentran vinculadas al tránsito ganadero, se reconocen algunos usos compatibles con este uso, asociados al tránsito agrícola, así como algunos usos complementarios relativos al disfrute y desarrollo natural, como son el paseo, el senderismo, la cabalgada y tránsito de vehículos no motorizados (artículos 16 y 17).

Esta Ley permite, además, la ubicación temporal de instalaciones desmontables asociadas a estos usos compatibles, previo informe municipal y autorización de la Comunidad Autónoma, que se sustituye mediante una simple declaración responsable del artículo 69 de la Ley 39/2015, de 1 de octubre, de Procedimiento Administrativo Común cuando se trate de "instalaciones vinculadas a una actividad de servicios", sin llegar a concretar cuáles resultan admisibles. 
Una previsión introducida por la Ley Omnibus, Ley 25/2009, de 22 de diciembre, que, no obstante, añadió la cautela en el párrafo tercero del artículo 17 de la Ley de Vías Pecuarias, de permitir restricciones complementarias cuando algunos usos "puedan suponer incompatibilidad con la protección de ecosistemas sensibles, masas forestales con alto riesgo de incendio, especies protegidas y prácticas deportivas tradicionales".

La Ley 8/1998, de 15 de junio, de Vías Pecuarias de la Comunidad de Madrid incorporó este uso de instalaciones desmontables asociadas a usos compatibles, con ocupación temporal de vías pecuarias, específicamente para la "prestación de servicios que faciliten los usos deportivos, recreativos y culturales de las vías pecuarias" (artículo 39.1).

De esta manera vinieron a ampliarse los usos compatibles en las vías pecuarias (al pasar del uso agrícola y deportivo, a usos recreativos y culturales) y, con ello, las instalaciones desmontables asociadas a este tipo de usos.

Pero, además, la Ley definió las instalaciones desmontables como aquéllas que:

“a) Por razones de seguridad precisen a lo sumo obras puntuales de cimentación que en ningún caso sobresaldrán del terreno y cuya eliminación tras la ocupación quede garantizada.

b) Estén constituidas por elementos de serie prefabricados, módulos, paneles 0 similares, sin elaboración de materiales en obra ni empleo de soldaduras.

c) Se monten y desmonten mediante procesos secuenciales cuyo levantamiento se realice sin demolición y siendo el conjunto de sus elementos fácilmente transportable".

De este modo, se incorporó la posibilidad de implantar, por ejemplo, puesto que es el más significativo, las llamadas carpas para bodas y otro tipo de eventos sociales de carácter recreativo, requiriéndose para ello título concesional por 10 años ampliables.

El resultado de la conjugación del régimen estatal y autonómico está servido: la implantación de este tipo de instalaciones desmontables es posible mediante la 
simple presentación de declaración responsable, tal y como contempla el artículo 46 del Reglamento aprobado, que deberá presentarse "con una antelación mínima de quince días a la fecha en la que se pretendan implantar las instalaciones desmontables a las que hace referencia dicha declaración responsable". Paradójicamente, en otros casos, la implantación de instalaciones desmontables sigue requiriendo concesión administrativa (artículos 47 y 48).

De esta manera se evidencia meridianamente cómo se aplican en la Comunidad de Madrid esos tres ejes sobre los que pivota el Reglamento aprobado, esto es: los principios de buena regulación, en particular el principio de proporcionalidad en las cargas administrativas, la agilización y flexibilización de la actuación administrativa, y la protección ambiental, aunque desconfiamos de si los es de los recursos naturales o de su aprovechamiento económico.

\section{2.- Resolución de 2 de febrero de 2021, de la Dirección General de} Sostenibilidad y Cambio Climático, por la que se aprueba el Plan de Acción contra el Ruido de la Red de Carreteras de la Comunidad de Madrid 2018-2023

Como la rúbrica indica, la actuación administrativa que referenciamos ahora, tiene por objeto aprobar el Plan de acción contra el ruido en la red de carreteras de la Comunidad de Madrid, para los años 2018-2023, aprobado de acuerdo con el régimen de la Ley 37/2003, de 17 de noviembre, del Ruido, el Real Decreto 1513/2005, de 16 de diciembre, de Evaluación y Gestión del Ruido Medioambiental, y el Real Decreto 1367/2007, de 19 de octubre, de desarrollo de la Ley 37/2003, en lo referente a zonificación acústica, objetivos de calidad y emisiones acústicas.

Una medida que no llega a tiempo, ni formal ni sustantivamente, pues conforme a la Disposición Adicional Primera de la Ley del Ruido debería haberse aprobado antes del día 18 de julio de 2013, y puesto que nos encontramos a dos años de la finalización del ámbito temporal del plan aprobado.

El Plan se aplica a carreteras con un volumen de tráfico superior a los 3.000 .000 de vehículos al año, y su cometido es o, de acuerdo con los mapas estratégicos de ruido previamente aprobados, establecer las acciones prioritarias para reducir los 
valores acústicos obtenidos allá donde hayan sido superados los límites acústicos establecidos, en particular en el entorno de grandes ejes viarios de la Comunidad de Madrid.

Al publicarse únicamente la resolución de aprobación del Plan, no hemos podido acceder por ningún medio electrónico a su contenido, por lo que pedimos disculpas. Una imposibilidad de acceder, por cierto, que vulnera claramente la publicidad activa de este tipo de planes, establecido específicamente en el artículo 7 de la Ley 27/2006, de 18 de julio, por la que se regulan los derechos de acceso a la información, de participación pública y de acceso a la justicia en materia de medio ambiente.

\section{3.- Resolución de 16 de febrero de 2021, del Director General de Biodiversidad} y Recursos Naturales, de la Consejería de Medio Ambiente, Ordenación del Territorio y Sostenibilidad, por la que se regula el tránsito por viales, el tránsito en las inmediaciones y pie de vía de sectores de escalada y la escalada en los sectores y vías regulados, en el paraje de La Pedriza del Parque Nacional de la Sierra de Guadarrama como medida de protección de especies rupícolas durante su época de cría y reproducción.

Como sucede periódicamente cada año, en cumplimiento de lo previsto en el Plan Rector de Uso y Gestión del Parque Nacional de la Sierra de Guadarrama, se aprueba la resolución que regula la escalada y tránsito en sus inmediaciones del paraje de la Pedriza, uno de los más frecuentados por los madrileños, más ahora en estos tiempos de pandemia con limitaciones perimetrales.

Se fija la atención, en particular, de que se produzcan daños a consecuencia de dichas actividades en los nidos de aves, concretamente de buitre leonado (Gyps fulvus), halcón peregrino (Falco peregrinus) y águila real (Aquila chrysaetos) y la necesidad de conservar estas aves en el período de cría.

Igualmente, se busca evitar posibles deterioros en la roca, daños en la base de la pared o en los senderos de acceso, fruto de la presencia de un gran número de escaladores. 
Por ello, la resolución establece una zonificación, que contempla áreas de restricción total de la escalada y el tránsito, y vías de escalada restringidas temporalmente. Fuera de esas zonas y determinados períodos, la resolución permite la práctica de la escalada, el bulder y el rápel.

Además, finalmente, se establece un sistema de información al escalador mediante señales en las propias vías y sectores, señales indicativas en aparcamientos y zonas de acceso, comunicación del personal del Parque Nacional en Centros de Visitantes y puntos de control de acceso, sin perjuicio de cuantos medios de comunicación se puedan articular para dar a conocer dicha regulación.

\section{4.- Orden 608/2021, de 10 de marzo, de la Consejería de Medio Ambiente,} Ordenación del Territorio y Sostenibilidad, sobre establecimiento de vedas y regulación especial de la actividad piscícola en los ríos, arroyos y embalses de la Comunidad de Madrid, para la temporada 2021

Como indica su propio título, la Orden regula el régimen de los permisos de pesca y tasas exigibles en los ríos, embalses y arroyos de la Comunidad de Madrid y, a tal efecto, diferencia distintos tipos de pescadores: integrantes de sociedad que gestionan cotos -y expiden permisos de pesca y devenga tasas por ello-, "ribereños" -esto es, residentes en municipios próximos a los cotos- y resto de pescadores. La Orden también fija las especies que pueden ser objeto de pesca (dimensiones mínimas y cupos), prohibiendo en particular las de Anguila (Anguilla anguilla), Barbo comizo (Barbus comizo), Calandino (Tropinophoxinellus - Squalius alburnoides), Lamprehuela o locha de calderón (Cobitis calderoni), Bermejuela (Rutilus arcasii), f) Colmilleja (Cobitis paludica), Pardilla (Rutilus lemmingii), y el cangrejo autóctono (Austropotamobius pallipes). Además, establece la Orden que Todos los ejemplares de trucha común capturados "deberán ser devueltos inmediatamente al agua evitando al máximo su manipulación".

Finalmente, se regulan las condiciones de la actividad pesquera y zonas donde puede desarrollarse (así como los periodos para solicitarlo), los periodos hábiles de 
pesca en 2021, el régimen de comercialización y el régimen sancionador por incumplimiento de sus prescripciones. 